\title{
Effects of Radioiodine Treatment on Salivary Gland Function in Patients with Differentiated Thyroid Carcinoma: A Prospective Study
}

\author{
Esther N. Klein Hesselink ${ }^{1}$, Adrienne H. Brouwers ${ }^{2}$, Johan R. de Jong ${ }^{2}$, Anouk N.A. van der Horst-Schrivers ${ }^{1}$, \\ Rob P. Coppes ${ }^{3}$, Joop D. Lefrandt ${ }^{4}$, Piet L. Jager ${ }^{5}$, Arjan Vissink ${ }^{6}$, and Thera P. Links ${ }^{1}$ \\ ${ }^{1}$ Department of Endocrinology, University of Groningen, University Medical Center Groningen, Groningen, The Netherlands; \\ ${ }^{2}$ Nuclear Medicine and Molecular Imaging, University of Groningen, University Medical Center Groningen, Groningen, The \\ Netherlands; ${ }^{3}$ Radiation Oncology and Cell Biology, University of Groningen, University Medical Center Groningen, Groningen, The \\ Netherlands; ${ }^{4}$ Vascular Medicine, University of Groningen, University Medical Center Groningen, Groningen, The Netherlands; \\ ${ }^{5}$ Department of Nuclear Medicine, Isala Hospital, Zwolle, The Netherlands; and ${ }^{6}$ Oral and Maxillofacial Surgery, University of \\ Groningen, University Medical Center Groningen, Groningen, The Netherlands
}

\begin{abstract}
Complaints of a dry mouth (xerostomia) and sialoadenitis are frequent side effects of radioiodine treatment in differentiated thyroid cancer (DTC) patients. However, detailed prospective data on alterations in salivary gland functioning after radioiodine treatment $\left({ }^{131} \mathrm{I}\right)$ are scarce. Therefore, the primary aim of this study was to prospectively assess the effect of high-activity radioiodine treatment on stimulated whole saliva flow rate. Secondary aims were to study unstimulated whole and stimulated glandular (i.e., parotid and submandibular) saliva flow rate and composition alterations, development of xerostomia, characteristics of patients at risk for salivary gland dysfunction, and whether radioiodine uptake in salivary glands on diagnostic scans correlates to flow rate alterations. Methods: In a multicenter prospective study, whole and glandular saliva were collected both before and 5 mo after radioiodine treatment. Furthermore, patients completed the validated xerostomia inventory. Alterations in salivary flow rate, composition, and xerostomia inventory score were analyzed. Salivary gland radioiodine uptake on diagnostic scans was correlated with saliva flow rate changes after radioiodine treatment. Results: Sixtyseven patients (mean age \pm SD, $48 \pm 17$ y; $63 \%$ women, $84 \%$ underwent ablation therapy) completed both study visits. Stimulated whole saliva flow rate decreased after ablation therapy (from 0.92 [interquartile range, $0.74-1.25$ ] to 0.80 [interquartile range, $0.58-1.18] \mathrm{mL} / \mathrm{min}, P=0.003$ ), as well as unstimulated wholeand stimulated glandular flow rates $(P<0.05)$. The concentration of salivary electrolytes was similar at both study visits, whereas the output of proteins, especially amylase $(P<0.05)$, was decreased. The subjective feeling of dry mouth increased $(P=0.001)$. Alterations in saliva flow rate were not associated with semiquantitatively assessed radioiodine uptake in salivary glands on diagnostic scans. For the small cohort of patients undergoing repeated radioiodine therapy, we could not demonstrate alterations in salivary parameters. Conclusion: We prospectively showed that salivary gland function is affected after high-activity radioiodine ablation therapy in patients with DTC. Therefore, more emphasis should be placed on salivary gland dysfunction during follow-up for DTC patients receiving high-activity radioiodine treatment.
\end{abstract}

Received Jan. 26, 2016; revision accepted May 17, 2016.

For correspondence contact: Thera P. Links, University of Groningen, University Medical Center Groningen, Department of Endocrinology, HPC AA31, P.O. Box 30.001, 9700 RB Groningen, The Netherlands.

E-mail: t.p.links@umcg.nl

Published online Jun. 23, 2016.

COPYRIGHT (c) 2016 by the Society of Nuclear Medicine and Molecular Imaging, Inc.
Key Words: differentiated thyroid cancer; radioiodine (131 I) treatment; salivary gland damage

J Nucl Med 2016; 57:1685-1691

DOI: 10.2967/jnumed.115.169888

$\mathbf{T}$ hyroid cancer is a common endocrine malignancy, with 62,450 expected cases in the United States for 2015, and is currently estimated to be the fifth most common cancer in women (1). Differentiated thyroid carcinoma (DTC), covering the papillary and follicular subtypes, is the most common malignancy of the thyroid. Patients with DTC have a favorable survival, which is presumably due to the relative indolent nature of the disease combined with an effective treatment consisting of a (near)-total thyroidectomy, radioiodine $\left({ }^{131} \mathrm{I}\right)$ treatment, and thyroid hormone suppression therapy. Adverse effects of treatment are increasingly being recognized, among them radioiodine-induced salivary gland damage (2).

The adverse effect of radioiodine on salivary glands is presumed to be related to the ability of salivary glands to concentrate (radio)iodine. This ability is probably facilitated by the sodiumiodide symporter, which is especially expressed in the striated ducts of the gland (3). Primary saliva is produced in the acini of the salivary glands and subsequently drains into the intercalated, striated, and excretory ducts. During the transport in the ductal system, the composition of saliva is actively changed, for example, sodium and chloride are reabsorbed, and potassium is excreted into the saliva. Because radioiodine is mainly concentrated in the ductal system, the $\beta$-radiation may generate luminal debris, which may cause ducts to narrow (4). These processes can lead to obstruction of the ductal system, causing an inflammatory response in the secretory tissue (sialoadenitis), and glandular degeneration (5). Moreover, salivary gland stem cells, which have been proposed to mainly reside in the excretory ducts $(6)$, may be affected because of the exposure to $\beta$-radiation resulting in a reduced regenerative potential (2).

Sialoadenitis can cause complaints of pain and swelling and result in an altered saliva composition. Ongoing sialoadenitis can 
lead to atrophy of the secretory parenchyma and salivary gland fibrosis, which may result in decreased saliva flow rates (hyposalivation), sensation of a dry mouth (xerostomia), and an increased risk of oral infections and dental caries (7). A further loss of salivary gland function due to stem cell damage may become clinically manifest after $60-120 \mathrm{~d}$, because this time is specific for salivary cell turnover $(8)$.

Previous studies focused on oral complaints that occur in roughly $30 \%$ of patients (9-11) and assessment of salivary gland function by ${ }^{99 m}$ Tc salivary scintigraphy $(12,13)$. Detailed, prospective data on salivary gland function by measurement of whole or glandular saliva flow rates (sialometry) including analysis of saliva composition (sialochemistry) are scarce for DTC patients (14). When such data are available, these may provide us with detailed knowledge on the effects of radioiodine treatment on salivary gland function.

The primary aim of this study was to assess the effect of highactivity radioiodine treatment on stimulated whole saliva flow rate when the acute effect has passed. Secondary aims were to study unstimulated whole and stimulated glandular saliva flow rate and composition, as well as xerostomia alterations after radioiodine treatment. Furthermore, we aimed to identify characteristics of patients at risk for salivary gland dysfunction and study whether radioiodine uptake in salivary glands as assessed on diagnostic scintigraphic and SPECT/CT scans correlates with posttherapy salivary gland dysfunction in radioiodine-treated DTC patients.

\section{MATERIALS AND METHODS}

\section{Design and Study Population}

We performed a multicenter prospective study in the 3 centers in the north of The Netherlands where patients with DTC are treated with radioiodine: the University Medical Center Groningen, Isala Clinics Zwolle, and the Medical Center Leeuwarden. The study was approved by the institutional ethics committee (METc 2013.039) and was registered at The Netherlands National Trial Register (NTR4354). All patients provided written informed consent.

All consecutive patients at least $18 \mathrm{y}$ old with DTC who were scheduled for radioiodine ablation (i.e., treatment targeting remnant normal thyroid tissue after thyroidectomy) or repeated high-activity radioiodine treatment were asked to participate in this study. Exclusion criteria were a history of Sjögren's syndrome or another salivary gland disease affecting baseline salivary gland function, oral ulceration, and radioiodine treatment preparation with recombinant human thyroidstimulating hormone (TSH). Preparation with recombinant human TSH was chosen as an exclusion criterion to ensure a homogeneous patient population and, moreover, the side effects of endogenous TSH stimulation are probably more profound. Included patients were scheduled for 2 study visits: the first at least $1 \mathrm{wk}$ before radioiodine treatment and the second approximately $5 \mathrm{mo}$ after treatment. The latter was chosen because after 5 mo the acute phase has passed, but patients are not yet scheduled for another radioiodine therapy, if necessary. At both study visits, whole and glandular saliva were collected, and patients completed a validated xerostomia inventory (XI) containing 11 multiple-choice questions related to xerostomia (15). In addition, data were collected on patient characteristics (supplemental materials [available at http://jnm.snmjournals.org]).

\section{Treatment and Follow-up}

Patients were treated according to the Dutch thyroid carcinoma guideline (supplemental materials) (16). In general, treatment included a (near)-total thyroidectomy with a central or lateral neck lymph node dissection if indicated. Four to $6 \mathrm{wk}$ after surgery, radioiodine ablation therapy was applied, usually with an activity of 3.7-5.5 GBq, depending on the risk stratification. All radioiodine therapies were performed under endogenous TSH stimulation, and patients were prescribed an iodinerestricted diet $1 \mathrm{wk}$ before the radioiodine treatment. Patients were advised to drink plenty of water and regularly use chewing gum or sour candies after administration of radioiodine therapy. No further recommendations about the time point of initiation, frequency, and duration of salivary gland stimulation were made, and no other salivary gland protection measures were applied.

\section{Saliva Collection}

During the 2 study visits, whole and glandular saliva were collected using standardized methods (supplemental materials). Unstimulated whole saliva was collected during $5 \mathrm{~min}$ by regularly spitting in a container. Thereafter, paraffin-stimulated whole saliva was collected in a similar fashion during $5 \mathrm{~min}$. During the glandular saliva collection, saliva of the left and right parotid and the submandibular/sublingual glands (later referred to as submandibular saliva) were separately collected for $10 \mathrm{~min}$. The salivary glands were stimulated by applying a cottonwool swab with $2 \%$ citric acid solution on both the lateral surfaces of the tongue every $30 \mathrm{~s}$.

\section{Sialochemistry}

Sodium and potassium were quantified using atomic emission spectrometry (Thermo Fisher Scientific, Inc.). Chloride, amylase, and total protein were measured using a modular analyzer (Roche) (supplemental materials).

\section{Imaging Protocol}

Planar whole-body imaging was performed $24 \mathrm{~h}$ after administration of $40 \mathrm{MBq}$ of radioiodine $\left({ }^{131} \mathrm{I}\right)$ before ablation planning or $72 \mathrm{~h}$ after administration of $74 \mathrm{MBq}$ of radioiodine ( $\left.{ }^{131} \mathrm{I}\right)$ for planning of repeated treatment. Posttherapy whole-body scans (WBS) were acquired $7 \mathrm{~d}$ after high-activity radioiodine $\left({ }^{131} \mathrm{I}\right)$ administration. SPECT/CT imaging of the head and neck was performed immediately after the posttherapy WBS (supplemental materials).

\section{lodine Uptake Measurement on Diagnostic Scans}

Iodine uptake in both parotid and submandibular glands was scored semiquantitatively on the planar pre- and posttherapy WBS. Furthermore, radioiodine uptake in the salivary glands was quantified on the posttherapy SPECT/CT scan. The radioiodine activity concentrated in each gland was expressed in $\mathrm{Bq}$ and $\mathrm{Bq} / \mathrm{mL}$ (supplemental materials).

\section{Statistical Analysis}

Data are presented as numbers with percentages, medians with interquartile ranges (IQRs), or means with $\mathrm{SD}$, as appropriate. Data were analyzed separately for patients who underwent ablation and repeated radioiodine treatment. Paired salivary flow rates (i.e., when both pre- and posttreatment measurements were available of a particular gland in the same individual) were compared using the Wilcoxon signed-rank test. In the case that gland dysfunction was observed at baseline, or when oral anatomy did not allow parotid saliva collection (of which a note was taken during measurement), the patient was excluded from the analysis with regard to the corresponding flow rate (supplemental materials). Alterations in saliva composition and XI scores were tested using the Wilcoxon signed-rank test for paired data.

We analyzed differences between patients (age, sex, TNM stage, tumor histology, and cumulative radioiodine activity) who did or did not have a decrease of at least $50 \%$ in stimulated whole saliva flow rate using the $\chi^{2}$ test, $t$ test, and nonparametric tests, as appropriate (supplemental materials).

Correlations between XI scores and the primary outcome parameter and between radioiodine uptake in parotid and submandibular glands and sialometry measures were tested using Spearman $\rho$.

All tests were 2 -sided, and a $P$ value of less than 0.05 was considered statistically significant. A Bonferroni-corrected $\alpha$ for multiple 
testing was used for analysis of individual XI questions. SPSS for Windows (version 22.0; IBM) was used for all analyses.

\section{RESULTS}

\section{Patients}

Ninety-five patients were approached for study participation, of whom 75 patients consented and were included in the study (Fig. 1). Eight patients were excluded, because of a cancellation of treatment $(n=7)$ or a change in radioiodine therapy preparation, from endogenous TSH stimulation to recombinant human TSH $(n=1)$. The remaining 67 patients (of whom 56 underwent ablation and 11 repeated radioiodine therapy) completed both study visits. The mean age of these patients was $47.7 \pm 17.1$ y. Fortytwo $(63 \%)$ patients were women (Table 1). An overview of the numbers of paired saliva measurements available for analysis is provided in Supplemental Figure 1.

Most patients (88\%) were treated with an activity of $5.55 \mathrm{GBq}$; cumulative radioiodine activities are shown in Supplemental Figure 2. The second study visit took place $5.3 \pm 0.6$ mo after radioiodine treatment.

\section{Sialometry}

In patients undergoing ablation therapy $(n=56)$, the stimulated whole saliva flow rate decreased from 0.92 (IQR, 0.74-1.25) to 0.80 (IQR, 0.58-1.18) $\mathrm{mL} / \mathrm{min}(P=0.003)$. Unstimulated whole and stimulated left and right parotid and submandibular flow rates decreased significantly as well (Table 2). In patients undergoing repeated radioiodine treatment $(n=11)$, stimulated whole saliva

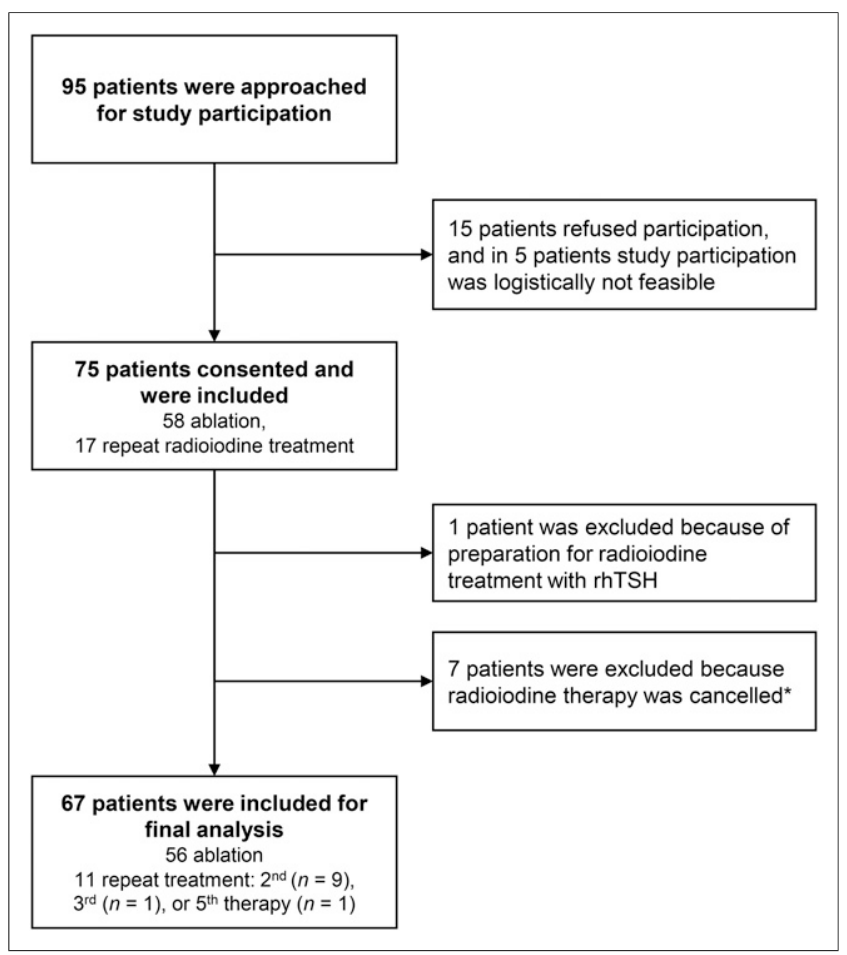

FIGURE 1. Flowchart. *In 1 patient radioiodine ablation treatment was cancelled when a malignancy other than DTC was found after revision of pathology report. In remaining 6 patients, repeated radioiodine therapy was cancelled after negative diagnostic WBS and thyroglobulin value $<1.0 \mathrm{ng} / \mathrm{mL}$ in absence of thyroglobulin antibodies. $\mathrm{rhTH}=$ recombinant human thyroid-stimulating hormone.
TABLE 1

Baseline Characteristics of DTC Patients with Paired Measurements Included for Final Analyses and All Patients Initially Included

\begin{tabular}{|c|c|c|}
\hline Characteristic & $\begin{array}{l}\text { Patients with } \\
\text { paired } \\
\text { measurements } \\
(n=67)\end{array}$ & $\begin{array}{l}\text { All included } \\
\text { patients } \\
(n=75)\end{array}$ \\
\hline Mean age \pm SD $(y)$ & $47.7 \pm 17.1$ & $48.6 \pm 17.2$ \\
\hline Female sex $(n)$ & $42(62.7)$ & $46(61.3)$ \\
\hline \multicolumn{3}{|l|}{ Histology (n) } \\
\hline Papillary & $54(80.6)$ & $58(77.3)$ \\
\hline Follicular & $7(10.4)$ & $10(13.3)$ \\
\hline Hürthle & $6(9.0)$ & $7(9.3)$ \\
\hline \multicolumn{3}{|l|}{ TNM tumor stage $(n)$} \\
\hline \multicolumn{3}{|l|}{ T stage } \\
\hline Tx-T2 & $41(61.2)$ & $45(60.0)$ \\
\hline T3 & $21(31.3)$ & 25 (33.3) \\
\hline T4 & $5(7.5)$ & $5(6.7)$ \\
\hline \multicolumn{3}{|l|}{$\mathrm{N}$ stage } \\
\hline $\mathrm{Nx}-\mathrm{NO}$ & $30(44.8)$ & $38(50.7)$ \\
\hline N1 & $37(55.2)$ & 37 (49.3) \\
\hline \multicolumn{3}{|l|}{ M stage } \\
\hline $\mathrm{Mx}-\mathrm{M} 0$ & $64(95.5)$ & $72(96.0)$ \\
\hline M1 & $3(4.5)$ & $3(4.0)$ \\
\hline \multicolumn{3}{|c|}{$\begin{array}{l}\text { Medications used } \\
\text { at first study visit }(n)\end{array}$} \\
\hline Oral $\beta$-blockers & $7(10.4)$ & $7(9.3)$ \\
\hline Diuretics & $8(11.9)$ & $9(12.0)$ \\
\hline $\begin{array}{l}\text { Neuropsychiatric } \\
\text { drugs }\end{array}$ & $8(11.9)$ & $10(13.3)$ \\
\hline Any $\geq 4$ medications & $23(34.3)$ & $26(34.7)$ \\
\hline \multicolumn{3}{|l|}{ Comorbidity (n) } \\
\hline Diabetes mellitus* & $4(6.0)$ & $5(6.7)$ \\
\hline Hypertension* & $16(23.9)$ & $18(24.0)$ \\
\hline Systemic diseases ${ }^{\dagger}$ & $2(3.0)$ & $2(2.7)$ \\
\hline \multicolumn{3}{|c|}{$\begin{array}{l}{ }^{*} \text { Defined as documented treatment for these conditions. } \\
{ }^{\circ} \text { Both patients had fibromyalgia. } \\
\text { Data in parentheses are percentages. }\end{array}$} \\
\hline
\end{tabular}

was $0.96(0.45-1.31)$ before and 0.53 (IQR, 0.39-1.54) $\mathrm{mL} / \mathrm{min}$ after treatment $(P=0.328)$. Unstimulated whole and stimulated glandular flow rates did not significantly change either. Supplemental Table 1 provides an overview of sialometry reference ranges.

There was a wide dispersion in baseline saliva flow rates and flow rate alterations after treatment (Fig. 2; Supplemental Fig. 3). Of the total study population, 23 patients $(34 \%)$ experienced a decrease of at least $25 \%$ in stimulated whole saliva flow rate, of which 7 had a decrease of more than $50 \%$ (Fig. 2), A higher cumulative radioiodine activity, but not age, sex, tumor histology, and TNM stage, was associated with a reduction in stimulated whole saliva flow rate of at least $50 \%(P=0.026)$. 
TABLE 2

Salivary Flow Rates of DTC Patients $(n=67)$ Before and After Radioiodine Therapy

\begin{tabular}{|c|c|c|c|}
\hline Salivary parameter & Before treatment (mL/min) & After treatment $(\mathrm{mL} / \mathrm{min})$ & $P$ \\
\hline \multicolumn{4}{|l|}{ Ablation patients $(n=56)$} \\
\hline Unstimulated whole saliva $(n=50)$ & $0.44(0.27-0.66)$ & $0.33(0.22-0.51)$ & 0.009 \\
\hline Paraffin-stimulated whole saliva $(n=56)$ & $0.92(0.74-1.25)$ & $0.80(0.58-1.18)$ & 0.003 \\
\hline Acid-stimulated left parotid saliva $(n=33)$ & $0.10(0.07-0.18)$ & $0.09(0.05-0.13)$ & 0.027 \\
\hline Acid-stimulated right parotid saliva $(n=29)$ & $0.10(0.07-0.16)$ & $0.06(0.02-0.11)$ & $<0.001$ \\
\hline Acid-stimulated SM saliva $(n=44)$ & $0.33(0.22-0.48)$ & $0.31(0.19-0.45)$ & 0.044 \\
\hline \multicolumn{4}{|l|}{ Repeated-therapy patients $(n=11)$} \\
\hline Unstimulated whole saliva $(n=10)$ & $0.32(0.18-0.48)$ & $0.26(0.09-0.47)$ & 0.169 \\
\hline Paraffin-stimulated whole saliva $(n=11)$ & $0.96(0.45-1.31)$ & $0.53(0.39-1.54)$ & 0.328 \\
\hline Acid-stimulated left parotid saliva $(n=6)$ & $0.26(0.16-0.35)$ & $0.14(0.06-0.26)$ & 0.249 \\
\hline Acid-stimulated right parotid saliva $(n=4)$ & $0.19(0.09-0.23)$ & $0.20(0.03-0.29)$ & 0.715 \\
\hline Acid-stimulated SM saliva $(n=10)$ & $0.47(0.33-0.66)$ & $0.25(0.16-0.71)$ & 0.059 \\
\hline
\end{tabular}

$\mathrm{SM}=$ submandibular gland saliva.

Numbers $(n)$ of patients with valid paired measurements (i.e., both a pre- and posttreatment measure were available of same patient and salivary gland) are indicated for the particular flow rates. Data in parentheses are IQRs.

\section{Sialochemistry}

Overall, clinically relevant differences were not observed in the pre- and postradioiodine treatment salivary concentrations of sodium, potassium, and chloride, whereas the output of total protein and amylase was reduced after ablation therapy (Table 3).

\section{$\mathbf{X I}$}

The score for "My mouth feels dry" significantly increased after ablation $(P=0.001)$, albeit there was no significant increase in the total XI score $(P=0.064)$ (Supplemental Table 2). Two patients $(4 \%)$ had xerostomia always or frequently before ablation treatment, as compared with 11 patients (20\%) after

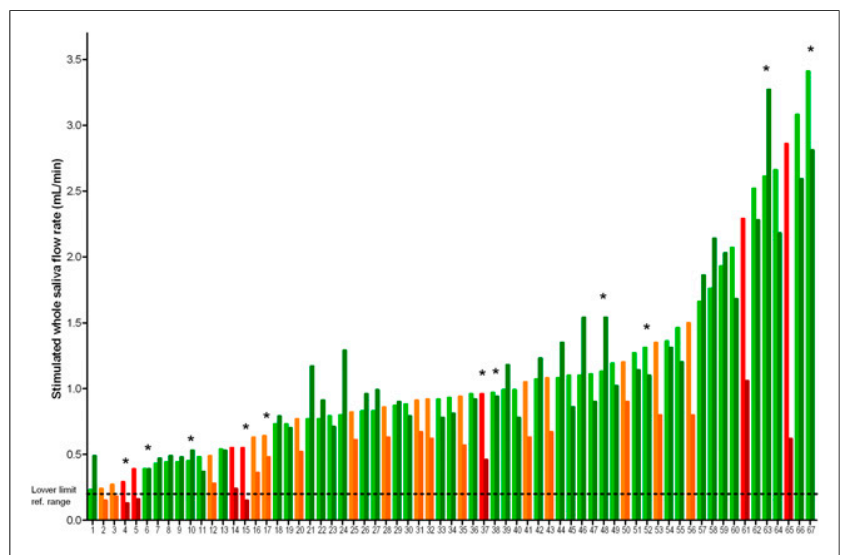

FIGURE 2. Displayed are changes in stimulated whole saliva flow rate for each of the 67 study subjects, ordered by basal flow rate. Lighter and paired darker bars represent flow rates before and after radioiodine treatment, respectively. Flow rate changes are color coded: green bars for subjects with less than $25 \%$ decrease, orange for $25 \%-50 \%$ decrease, and red for $>50 \%$ decrease in stimulated whole saliva flow rate. *Patients who underwent repeated radioiodine treatment. therapy (Table 4). The pre- and posttherapy XI scores of patients receiving repeated therapy were similar. The posttherapy XI score was related to posttherapy stimulated whole saliva flow rate (Supplemental Fig. 4).

\section{Salivary Gland Radioiodine Uptake on Diagnostic Scans}

In Figure 3, a case is presented with clear accumulation of radioiodine in the salivary glands on the SPECT/CT scan, which was performed $7 \mathrm{~d}$ after ablation therapy. Semiquantitatively assessed radioiodine uptake in the parotid and submandibular glands on the pre- and posttherapy WBS did not correlate with saliva flow rate alterations after radioiodine treatment (Supplemental Table 1). Quantitatively assessed uptake of radioiodine in the salivary glands (expressed in $\mathrm{Bq}$ and $\mathrm{Bq} / \mathrm{mL}$ ) did not correlate with alterations in saliva flow rates either (Supplemental Table 2).

\section{DISCUSSION}

In the current prospective study, we found a decreased salivary gland function in DTC patients 5 mo after high-activity radioiodine ablation therapy with endogenous TSH stimulation, as compared with preablation. Salivary flow rates decreased, the lowered output of amylase indicated acinar dysfunction, and patients had an increased subjective feeling of a dry mouth after ablation therapy. Overall xerostomia-related morbidity was limited though, and salivary gland dysfunction was not a universal problem because there was a wide dispersion in flow rate alterations after radioiodine treatment. We did not find evidence for sialoadenitis 5 mo after treatment, because the concentration of salivary electrolytes was not altered. Uptake of radioiodine in the salivary glands on diagnostic scans did not correlate to flow rate alterations after treatment, and in the small group of patients who underwent repeated treatments no alterations in salivary parameters were found.

Previous studies on sialometry analyses in DTC patients are scarce. In 1 prospective study, parotid saliva composition alterations that correspond to an acute sialoadenitis were found $1 \mathrm{wk}$ after radioiodine treatment (14), whereas 2 cross-sectional studies on 
TABLE 3

Salivary Composition of Patients with DTC $(n=67)$ Treated with Ablation and Repeated Radioiodine Therapy

\begin{tabular}{|c|c|c|c|}
\hline Salivary parameter & Before radioiodine therapy & After radioiodine therapy & $P$ \\
\hline \multicolumn{4}{|l|}{ Ablation patients $(n=56)$} \\
\hline \multicolumn{4}{|l|}{ Total protein (mg/min) } \\
\hline Unstimulated whole saliva $(n=44)$ & $0.18(0.11-0.32)$ & $0.15(0.09-0.21)$ & 0.031 \\
\hline Chewing-stimulated whole saliva $(n=56)$ & $0.40(0.27-0.61)$ & $0.32(0.20-0.46)$ & 0.001 \\
\hline Acid-stimulated parotid saliva $(n=41)$ & $0.05(0.02-0.08)$ & $0.03(0.02-0.06)$ & 0.101 \\
\hline Acid-stimulated SM $(n=49)$ & $0.05(0.02-0.08)$ & $0.04(0.02-0.07)$ & 0.126 \\
\hline \multicolumn{4}{|l|}{ Amylase (U/min) } \\
\hline Unstimulated whole saliva $(n=44)$ & $55.4(27.9-111)$ & $37.7(19.1-78.6)$ & 0.017 \\
\hline Chewing-stimulated whole saliva $(n=56)$ & $161(101-259)$ & $116(48.4-192)$ & 0.006 \\
\hline Acid-stimulated parotid saliva $(n=37)$ & $25.5(11.0-46.7)$ & $16.2(7.4-30.0)$ & 0.023 \\
\hline Acid-stimulated SM $(n=48)$ & $11.7(5.4-26.2)$ & $10.5(4.3-20.2)$ & 0.028 \\
\hline \multicolumn{4}{|l|}{ Repeated-treatment patients $(n=11)$} \\
\hline \multicolumn{4}{|l|}{ Total protein (mg/min) } \\
\hline Unstimulated whole saliva $(n=9)$ & $0.13(0.06-0.38)$ & $0.09(0.06-0.27)$ & 0.859 \\
\hline Chewing-stimulated saliva $(n=11)$ & $0.33(0.19-0.49)$ & $0.26(0.16-0.60)$ & 0.424 \\
\hline Acid-stimulated parotid saliva $(n=7)$ & $0.05(0.02-0.11)$ & $0.03(0.01-0.09)$ & 0.600 \\
\hline Acid-stimulated SM $(n=11)$ & $0.06(0.04-0.13)$ & $0.03(0.02-0.10)$ & 0.021 \\
\hline \multicolumn{4}{|l|}{ Amylase (U/min) } \\
\hline Unstimulated whole saliva $(n=9)$ & $37.3(16.0-136)$ & $20.8(10.2-110)$ & 0.028 \\
\hline Chewing-stimulated whole saliva $(n=11)$ & $131(90.6-187)$ & $139(6.4-266)$ & 0.328 \\
\hline Acid-stimulated parotid saliva $(n=7)$ & $28.9(9.3-57.9)$ & $20.7(6.9-63.1)$ & 0.463 \\
\hline Acid-stimulated SM $(n=11)$ & $11.6(7.0-48.2)$ & $5.3(3.6-51.6)$ & 0.248 \\
\hline
\end{tabular}

$\mathrm{SM}=$ submandibular gland saliva.

Numbers $(n)$ of patients with valid paired measurements are indicated, dependent on saliva quantity. Data in parentheses are IQRs.

long-term effects of radioiodine treatment on whole saliva flow rates in DTC patients showed contradictory results $(17,18)$. Studies using salivary gland scintigraphy, which assesses both the uptake and the excretion ability of the gland, are more abundant $(12,13,19)$. In most studies an affected gland function was found after radioiodine therapy $(12,19)$, although in a recent paper this was found only after activities higher than $5.55 \mathrm{GBq}(13)$.
It is hard to precisely indicate the percentage of DTC patients who suffer from salivary gland damage after radioiodine treatment, because a uniform definition of this condition is lacking. A decrease of more than $50 \%$ in saliva flow rate is generally regarded as the critical value for initiation of oral complaints (20). Ten percent of patients had such a decrease in stimulated whole saliva flow rate after radioiodine treatment. Approximately one third of patients

TABLE 4

Numbers of Patients Treated with Radioiodine Ablation and Repeated Treatment Who Indicated Several Extents of Xerostomia Before and After Treatment

\begin{tabular}{|c|c|c|c|c|}
\hline \multirow{2}{*}{$\begin{array}{l}\text { Response to the question: } \\
\text { My mouth feels dry }\end{array}$} & \multicolumn{2}{|c|}{$\begin{array}{l}\text { Radioiodine ablation } \\
\text { treatment }(n=56)\end{array}$} & \multicolumn{2}{|c|}{$\begin{array}{l}\text { Repeated radioiodine } \\
\text { treatment }(n=11)\end{array}$} \\
\hline & Before therapy $(n)$ & After therapy $(n)$ & Before therapy $(n)$ & After therapy $(n)$ \\
\hline Never & 19 (34) & $9(16)$ & $3(27)$ & $3(27)$ \\
\hline Hardly ever & $18(32)$ & $20(36)$ & 0 & $2(18)$ \\
\hline Occasionally & $17(30)$ & $16(29)$ & $5(46)$ & $3(27)$ \\
\hline Frequently & $2(4)$ & $7(13)$ & $2(18)$ & $3(27)$ \\
\hline Always & 0 & $4(7)$ & $1(9)$ & 0 \\
\hline
\end{tabular}

Data in parentheses are percentages. 


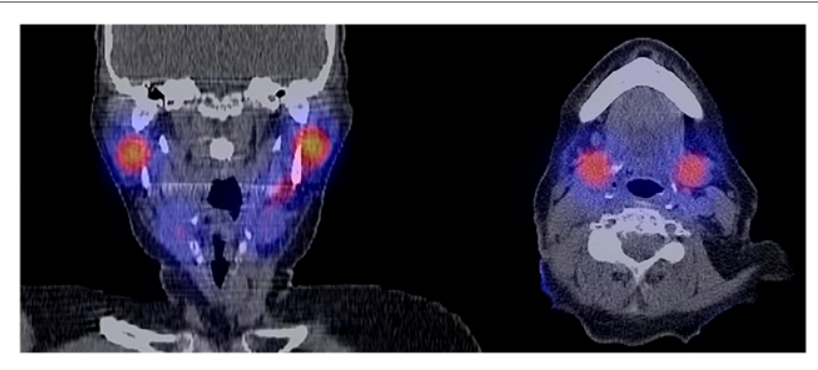

FIGURE 3. Uptake of radioiodine in parotid (left) and submandibular (right) glands on SPECT/CT scan, performed $7 \mathrm{~d}$ after radioiodine therapy.

had a decrease of at least $25 \%$, which could already be relevant to this population because baseline saliva flow rates were rather low (20). The latter can possibly be explained by the gradually increasing hypothyroid state after endogenous TSH stimulation, which has been associated with reduced saliva secretion (21). Although study visits took place at least $1 \mathrm{wk}$ before radioiodine therapy to limit the effect of hypothyroidism, it may still have affected baseline saliva flow rates. Other factors such as medication use (22), or increased emotional stress after DTC diagnosis (23), may also have contributed to rather low baseline saliva secretion rates. Despite this, we were still able to find a decrease in flow rates at the second study visit when patients were in a euthyroid or (subclinical) hyperthyroid state due to thyroid hormone substitution, which emphasizes the adverse effects of radioiodine on saliva secretion.

The subjective feeling of a dry mouth increased after ablation therapy, although xerostomia-related morbidity was still limited. This may be explained by the finding that only 7 patients experienced a decrease in stimulated whole saliva flow rate of more than $50 \%$ that generally results in xerostomia (20). However, a decrease in stimulated saliva flow rate between $25 \%$ and $50 \%$ was common. This may progress and cause more pronounced oral complaints in the case of further radioiodine treatment for high-risk patients. On the other hand, reversibility of salivary gland dysfunction is not precluded because a regenerative capacity for the parotid glands has been suggested based on data from patients treated with external radiotherapy for head and neck cancer ( 6 ).

We did not find convincing associations between radioiodine uptake in salivary glands on diagnostic planar and SPECT/CT scans and alterations in flow rate of the particular glands, despite detailed evaluations of radioiodine uptake in salivary glands on several scans. Possibly, an explanation for this may be the nondynamic nature of the scans (24), or a patient-specific regeneration capacity of the salivary glands. Altogether, these data indicate that it is hard to predict salivary gland dysfunction after radioiodine treatment using scans that are routinely performed.

A limitation of this study is that patients were assessed during different degrees of hypo- to hyperthyroidism at the 2 study visits, which may have influenced salivary gland function. Furthermore, we intended to evaluate the effects of repeated radioiodine therapy on salivary gland function as well, but within the inclusion period an insufficient number of patients underwent repeated therapy with endogenous TSH stimulation to gain sufficient statistical power. Unfortunately, extension of the inclusion period with several more years was not feasible. Additionally, we did not routinely record in all patients whether they had experienced clinical signs of acute and chronic sialoadenitis, and our secondary outcomes are less robust than our primary outcome, because of the exclusion of several patients for especially glandular saliva flow rate analyses (which may have led to a selection of patients with normal baseline flow rates) and incomplete nuclear scan data.

\section{CONCLUSION}

Salivary gland function is affected after radioiodine ablation therapy. Although overall morbidity was limited and salivary gland dysfunction after single high-activity radioiodine treatment does not seem to be a universal problem, approximately $10 \%$ of patients experience a steep decline in stimulated whole saliva flow rate. Therefore, more emphasis should be placed on salivary gland dysfunction during DTC follow-up, and early referral to a dentist or oral medicine specialist should be considered when patients suffer from xerostomia-related complaints. This is especially important for patients at high risk for residual, recurrent, or metastatic DTC who are expected to receive high-activity radioiodine therapy repeatedly with endogenous TSH stimulation and those with a preexistent decreased salivary function, to maintain quality of life after radioiodine treatment.

\section{DISCLOSURE}

The costs of publication of this article were defrayed in part by the payment of page charges. Therefore, and solely to indicate this fact, this article is hereby marked "advertisement" in accordance with 18 USC section 1734 . No potential conflict of interest relevant to this article was reported.

\section{ACKNOWLEDGMENTS}

We are grateful to all patients who participated in this study and to the contributions of Dr. Ha T.T. Tan-Phan, Department of Nuclear Medicine, Medical Center Leeuwarden, Leeuwarden, The Netherlands, and Dr. Wilhelmina H.A. de Jong, Laboratory Medicine, University Medical Center Groningen, Groningen, The Netherlands.

\section{REFERENCES}

1. Siegel RL, Miller KD, Jemal A. Cancer statistics, 2015. CA Cancer J Clin. 2015;65:5-29.

2. Klein Hesselink EN, Links TP. Radioiodine treatment and thyroid hormone suppression therapy for differentiated thyroid carcinoma: adverse effects support the trend toward less aggressive treatment for low-risk patients. Eur Thyroid J. 2015;4:82-92.

3. La Perle KM, Kim DC, Hall NC, et al. Modulation of sodium/iodide symporter expression in the salivary gland. Thyroid. 2013;23:1029-1036.

4. Mandel SJ, Mandel L. Radioactive iodine and the salivary glands. Thyroid. 2003;13:265-271.

5. Van Nostrand D. Sialoadenitis secondary to ${ }^{131} \mathrm{I}$ therapy for well-differentiated thyroid cancer. Oral Dis. 2011;17:154-161.

6. van Luijk P, Pringle S, Deasy JO, et al. Sparing the region of the salivary gland containing stem cells preserves saliva production after radiotherapy for head and neck cancer. Sci Transl Med. 2015;7:305ra147.

7. Walter MA, Turtschi CP, Schindler C, Minnig P, Muller-Brand J, Muller B. The dental safety profile of high-dose radioiodine therapy for thyroid cancer: longterm results of a longitudinal cohort study. J Nucl Med. 2007;48:1620-1625.

8. Vissink A, Mitchell JB, Baum BJ, et al. Clinical management of salivary gland hypofunction and xerostomia in head-and-neck cancer patients: successes and barriers. Int J Radiat Oncol Biol Phys. 2010;78:983-991.

9. Hyer S, Kong A, Pratt B, Harmer C. Salivary gland toxicity after radioiodine therapy for thyroid cancer. Clin Oncol (R Coll Radiol). 2007;19:83-86.

10. Alexander C, Bader JB, Schaefer A, Finke C, Kirsch CM. Intermediate and longterm side effects of high-dose radioiodine therapy for thyroid carcinoma. $\mathrm{J} \mathrm{Nucl}$ Med. 1998;39:1551-1554. 
11. Jensen SB, Pedersen AM, Vissink A, et al. A systematic review of salivary gland hypofunction and xerostomia induced by cancer therapies: prevalence, severity and impact on quality of life. Support Care Cancer. 2010; 18:1039-1060.

12. Solans R, Bosch JA, Galofre P, et al. Salivary and lacrimal gland dysfunction (sicca syndrome) after radioiodine therapy. J Nucl Med. 2001;42:738-743.

13. Wu JQ, Feng HJ, Ouyang W, et al. Systematic evaluation of salivary gland damage following I-131 therapy in differentiated thyroid cancer patients by quantitative scintigraphy and clinical follow-up. Nucl Med Commun. 2015; 36:819-826.

14. Maier H, Bihl H. Effect of radioactive iodine therapy on parotid gland function. Acta Otolaryngol. 1987;103:318-324.

15. Thomson WM, Chalmers JM, Spencer AJ, Williams SM. The xerostomia inventory: a multi-item approach to measuring dry mouth. Community Dent Health. 1999;16:12-17.

16. Comprehensive Cancer Centre the Netherlands. Oncoline, cancer clinical practice guidelines. Oncoline website. http://www.oncoline.nl/index.php?language =en. Accessed July 13, 2016.

17. Laupa MS, Toth BB, Keene HJ, Sellin RV. Effect of radioactive iodine therapy on salivary flow rates and oral streptococcus mutans prevalence in patients with thyroid cancer. Oral Surg Oral Med Oral Pathol. 1993;75:312-317.
18. Almeida JP, Sanabria AE, Lima EN, Kowalski LP. Late side effects of radioactive iodine on salivary gland function in patients with thyroid cancer. Head Neck. 2011;33:686-690.

19. Jeong SY, Kim HW, Lee SW, Ahn BC, Lee J. Salivary gland function 5 years after radioactive iodine ablation in patients with differentiated thyroid cancer: direct comparison of pre- and postablation scintigraphies and their relation to xerostomia symptoms. Thyroid. 2013;23:609-616.

20. Ship JA, Fox PC, Baum BJ. How much saliva is enough? 'Normal' function defined. J Am Dent Assoc. 1991;122:63-69.

21. Muralidharan D, Fareed N, Pradeep PV, Margabandhu S, Ramalingam K, Ajith Kumar BV. Qualitative and quantitative changes in saliva among patients with thyroid dysfunction prior to and following the treatment of the dysfunction. Oral Surg Oral Med Oral Pathol Oral Radiol. 2013;115:617-623.

22. Aliko A, Wolff A, Dawes C, et al. World workshop on oral medicine VI: clinical implications of medication-induced salivary gland dysfunction. Oral Surg Oral Med Oral Pathol Oral Radiol. 2015;120:185-206.

23. Gemba H, Teranaka A, Takemura K. Influences of emotion upon parotid secretion in human. Neurosci Lett. 1996;211:159-162.

24. Lee SM, Lee JW, Kim SY, Han SW, Bae WK. Prediction of risk for symptomatic sialadenitis by post-therapeutic dual ${ }^{131} \mathrm{I}$ scintigraphy in patients with differentiated thyroid cancer. Ann Nucl Med. 2013;27:700-709. 